\title{
Internal and External Factors Affecting Learning English as a Foreign Language
}

\author{
Soheil Mahmoudi ${ }^{1}$, Asgar Mahmoudi ${ }^{2}$, \\ ${ }^{1}$ Department of English Language, Ahar Branch, Islamic Azad University, Ahar, Iran \\ ${ }^{2}$ Department of English Language, Ardabil Branch, Islamic Azad University, Ardabil, Iran
}

Email address:

Soheilmahmoudi70@gmail.com (S. Mahmoudi), Mahmoudi301@gmail.com (A. Mahmoudi)

\section{To cite this article:}

Soheil Mahmoudi, Asgar Mahmoudi. Internal and External Factors Affecting Learning English as a Foreign Language. International Journal of Language and Linguistics. Vol. 3, No. 5, 2015, pp. 313-322. doi: 10.11648/j.ij11.20150305.16

\begin{abstract}
This study investigated the effects of internal and external factors on learning English as a foreign language from Iranian EFL learners' points of view. Copies of a 30-item Lickert-scale questionnaire, addressing internal and external factors or principle components, were distributed among about 140 postgraduate students of ELT in three universities in Iran. The collected data were then subjected to Principle Component Analysis (PCA). The findings revealed that while internal and external components are distinguishable, many of the variables do not heavily load on the principle component to which they theoretically belong. After separating the non-correlating variables it became clear that most of these variables are very important variables. Further analysis indicated that it is possible to divide internal variables to cognitive and affective and external variables to environmental and curricular. The conclusion reached was that the importance of variables should not be judged based on their nature but based on the importance accorded to them by the respondents. It was also concluded that extreme attention paid to internal variables should be balanced against external variables.
\end{abstract}

Keywords: Principle Component Analysis, Internal Variables, External Variables

\section{Introduction}

\subsection{Overview}

This survey study was designed to explore factors or principle components affecting Iranian EFL learners' success from their own perspectives. The study also probed into these components relationships with variables loading on them. The roles of internal and external factors or components in the acquisition of second or foreign language have been broadly investigated in the past (e.g., Brown, 1995; Ellis, 2008; Nunan, 1988; Ortega, 2009). However, in many cases the boundaries between these two principle components and the way their respective variables load on them are left unexplored. For example, while anxiety and attitude are internal variables, they can be heightened or weakened by external variables. On the other hand, shortcomings in the external variables, such as unfavorable institutional context, can be compensated for by the autonomy (an internal variable) that a student has. Therefore, there might be interactions between these two groups of variables and they may reciprocally affect each other. Exploring these kinds of relationships was the main concern of this research.

\subsection{Statement of the Problem and Significance of the Study}

Looking through research articles, journals, and books one can see that countless research has been conducted on the internal and external factors or principle components affecting second or foreign language acquisition. However, the question of the interactions between these two groups of variables is given little attention. Robinson and Ellis (2008) indicate that all these variables are inextricably intertwined in a rich, complex, and dynamic way in languages. The purpose of categorization, therefore, is only to understand the situation better not to claim that these factors have nothing to do with each other. Foreign language learners themselves too have not been asked to express their views over these issues very frequently, as the majority of research in the field has been experimental in nature. This study aimed at bridging the gaps in these two areas feeling that this might provide a deeper understanding of what is going on in EFL environments. Moreover, it tried to find out if it is correct to look at the internal and external factors as separate groups of variables having no interaction with each other. Still more, the study tried to investigate the subdivisions of the internal 
and external factors to see if they are further divisible into cognitive and affective and curricular and environmental, respectively.

\subsection{Significance of the Study}

A more profound understanding of the internal and external principle components, and articulating them at some detail with a reference to their due shares in developing second or foreign language proficiency, will certainly help all stakeholders to make wiser decisions. In particular administrators and people in charge of directing the educational system will know where to invest their time, energy, and money. Students too can regulate their own learning processes by the enhanced awareness that would result. Many a time students do not know why they are not making the progress they think they should with respect to all their efforts. Parents, too, sometimes get frustrated by their children's sluggish progress because of the poor understanding that they have of the so many variables affecting their children's performance. And even many teachers get bogged down with all good intentions that they bring to the process of teaching and learning. This study is significant because it was designed to tell these people why sometimes things go wrong. It is also significant because it was an effort to provide clear understanding of the most important variables that from learners' perspectives affect their learning of a foreign language, in this case English.

\subsection{Design of the Study}

This study was conducted following an ex post facto design due to the fact that the variables and their clustering and inter-correlations were thought to be present prior to the beginning of the study. This means that, the study did not involve any interference and merely tried to identify the clustering and patterns of interactions that existed among the foreign language learning variables from the respondents' perspectives. Similar to experimental studies this design only explains the consequent of a condition. Unlike experimental studies, however, it does not let the researcher manipulate the variables of the study.

\section{Review of the Related Literature}

\subsection{Introduction}

Looking at all variables affecting foreign language learning simultaneously would be a little bit difficult. It seems logical to classify these factors into two groups of internal and external that include elements of the same type (Madrid, 1995). External factors are largely dealt with in books dealing with curriculum development and course design (e.g., Dean Brown, 1995; Lewis \& Hill, 1985; Nation \& Macalister, 2010; Nunan, 1988; Richards, 2001; White, 1988) while internal factors are discussed in SLA and psychology books (e.g., Brown, 2007; Robinson \& Ellis, 2008; Gass \& Selinker, 2008; Ortega, 2009; Woolfolk, Winne, \& Perri, 2003).

\subsection{Internal Variables}

Internal variables imply cognitive and affective factors such as motivation, intelligence, anxiety, risk-taking ability, etc. Because of space limitation, only some of these variables are elaborated on here.

Many studies have confirmed that motivation correlates strongly with proficiency, indicating both that successful learners are motivated and that success improves motivation. Motivation has been recognized as an important variable determining L2 achievement and attainment for a long time. Motivation is believed to act as an engine generating learning and then propelling students forward helping them overcome the difficulties they encounter in learning a foreign language (Cheng and Dörnyei, 2007; Dörnyei and Csizer, 1998). Brown (2007) considers motivation as an affective factor that plays a central role in learning a second or foreign language. Cohen (2010) sees motivation as a dynamic process that is not stable but is in a continuous change.

Language learners' attitudes toward the language being learned, likewise, can have a significant impact on SLA. Where the community has a broadly negative view of the target language and its speakers, or a negative view of its relations to them, learning is typically much more difficult (Gardner, 1985; "Attitude," 2009). According to Siegel (2003), motivation is affected by learners' attitudes toward the L2, its speakers, and the speakers' culture.

Extraversion and introversion are two personality types that fall within the brief of internal variables. Studies have revealed that extraverts acquire a second language better than introverts. Gregarious people usually tend to communicate with others even if they are not sure they will succeed (Kinginger and Farell, 2004).

\subsection{External Variables}

Among external variables one can refer to such variables as social class, first language, teachers, early start, L2 curriculum, etc. Generally speaking, external variables can be categorized into the two groups of environmental and curricular but the list of external variables referred to here, like the list of internal variables, is not exhaustive, as in many other studies. Nation and Macalister (2010), for example, in discussing the importance of curricular issues, highlight the importance of needs analysis, sequencing the course materials, evaluation, format and presentation of materials. Richards (2001) too emphasizes the roles of institutions, teachers, and learners in providing for effective learning.

Teacher behavior definitely influences all kinds of learning especially learning a foreign language. According to Cheng and Dörnyei (2007), teachers can fire students' enthusiasm by being a personal model in the class. Stipek (2002), also points to the importance of the teachers' projection of enthusiasm. With the development of technology the Internet is playing a more and more important role in learning English. English students are downloading English songs, and films that let them get exposure to real English at a globalized 
communicational level (Nurul Islam, 2011). The Internet is much more than this. All people around the globe, especially students, use it to do research, to access library materials, online quizzes, podcasts, and the like (Khanchali, \& Ziadat, 2011).

It has been agreed on the fact that there should be some sort of variety in EFL learning. One way of bringing variety into EFL classes is the use of films (Ismaili, 2013). It is revealed that L2 learners who do not possess the same linguistic base as the L1 face a lot of difficulties. The difficulties get bigger when there is a bigger difference between L1 and L2 (Karim, 2003; Segalowitz 1986). One of the ways to cope with this problem is integrating English films, sometimes manipulated for pedagogical purposes, into the teaching process.

\section{Method}

\subsection{Introduction}

In the case of EFL, a lot of questions can be asked that roughly can be divided into questions addressing internal or external variables. However, the loading of each of these questions on the main construct and its subdivisions will not be clear unless a PCA is run on the collected data. This is because responses to questions or the importance assigned to each variable in a questionnaire are situation and person specific and vary from one situation and person to the other. It is only after running a PCA that patterns of groupings in that particular context emerge. On the other hand, researchers might be interested in finding out if the principle components they identify after running a PCA can be further subdivided into additional specific components. This is possible in two ways: impressionistically and by running additional PCAs. Impressionistic grouping of variables has the danger that the variables might not load on the component that the researcher thinks they should even if they are conceptually and theoretically related. Running a PCA, in contrast, increases the precision and brings to the surface things that otherwise might remain unnoticed.

\subsection{Research Questions and Hypotheses}

Following from what was said, this research tried to find out if all of the variables in each category load on the principle component to which they are attributed and if not why. The study, in other words, tried to answer the questions 'Do all variables that are theoretically considered to be internal correlate significantly with each other? Do all variables that are theoretically considered to be external correlate significantly with each other? Are there any internal and external variables that correlate significantly with each other or with the other principle component? Are internal variables divisible to cognitive and affective? Are external variables divisible to curricular and environmental? How the answers to these questions can be justified?

The null research hypotheses that were derived from these questions are as follows:
$\mathrm{H}_{0} 1$ : All variables that are theoretically considered to be internal or external do not necessarily correlate significantly with variables of their own type.

$\mathrm{H}_{0} 2$ : There are no internal and external variables that correlate significantly with each other or with the principle component to which they do not belong.

$\mathrm{H}_{0} 3$ : Internal and external variables are not treated, i.e., rated differently by EFL learners with respect to their importance.

$\mathrm{H}_{0} 4$ : Internal and external variables are divisible to cognitive and affective and curricular and environmental, respectively, with regard to the amount of importance that students assign to them.

\subsection{Participants}

The participants of this study were all Master's degree students of English Language Teaching (ELT) in three universities in northwest Iran, two in the provincial city of Ardabil, and one in Ahar city. Naturally, all of the students were above 22 years old and had an English language learning experience of at least five years. A great majority of the participants were fluent bilinguals of Persian and Azeri but there were a few of them who did not know Azeri well. No screening for proficiency was done before beginning of the research because the research was not intended to measure the participants' gains in proficiency over time rather to elicit their opinions about the importance of variables affecting learning English as a foreign language.

\subsection{Instruments}

The instruments used in this study were of three types. The first instrument was a 5-point Likert scale questionnaire containing 30 questions. The questions were of two types related to internal and external variables that could be further sub-divided into cognitive and affective in the case of internal variables and curricular and environmental in the case of external variables. All of the questions were derived from research articles and a rough balance was established with respect to the number of questions addressing each variable type. The values of responses to each question ranged from 1 to 5 . One represented the least effect and five represented the most effect. The questionnaire was designed to give the fullest possible coverage to the variables that, according to the literature on the field, affect learning English as a foreign language but the length of the questionnaire was kept in control not to exceed the limit that might have discouraged the respondents from answering all of the questions with enough attention.

Another type of instrument used in this study was Microsoft Office's Excel spreadsheet that was used to calculate the means of responses to each question in the questionnaire. These means at the later stages of the study, when the variables were divided into two components, were used as distributions of mean scores to run an Independentsamples T-test between the two groups of variables to discover if according to students' responses they were 
significantly different from each other.

The last instrument used was the SPSS package that was used to analyze the collected data. As a prerequisite of descriptive studies, it was necessary to check for the reliability of the questionnaire. Further, it was necessary to run an exploratory PCA to find out if any variable, from participants' points of view, was exerting undue influence upon foreign language learning. The findings would also be much more understandable if they could be represented diagrammatically. SPSS was used to do all these things.

\subsection{Procedure}

Since some respondents answer questions in a questionnaire superficially, it was decided that if anyone's responses were the same for more than one-third of the questions in the questionnaire, that copy of the questionnaire be discarded from the study. For this reason, although initially more than 160 copies of the questionnaire were distributed among the MA students, the ultimate number of copies used in the data analysis was 136 .

Of the 30 questions in the questionnaire 15 were targeted at the internal variables and 15 at the external variables but not to let out the purpose of the study, the questions were arranged in an odd-even order with odd questions addressing the internal variables and even questions addressing the external variables. The organization of the questions relating to subdivisions of the internal and external variables was random.

After the questions were answered and the data were collected, they were entered into SPSS. SPSS recognizes each question in a questionnaire as a single variable and deals with it accordingly. After the data inputting and as the first stage a Chronbach Alpha reliability test was run to find out if the questionnaire was reliable. After that, a PCA with two principle components on the overall data and then two more PCAs on each major group of variables again with two principle components were run with Scree and Component plots to test the hypotheses of the study.

PCA, according to Pallant (2013), is a data reduction technique that looks for a way a huge collection of data may be reduced or summarized. The purpose of this study, however, was to single out variables that did not correlate with each other even though they belong to the same category theoretically and explain why this might have been the case.

PCA produces a series of tables and numbers that enable researchers to find answers to their questions. Two of the tables include measures of sampling adequacy and measures of PCA appropriateness. An important number is determinant of the correlation matrix. This number checks for the existence of multicolinarity (correlations above .8 between variables) and singularity (perfect correlations between variables). SPSS provides this value at the bottom of the correlation matrix. Determinant's value should be significantly different from zero.

PCA also produces two very informative plots. The first of these plots is called the Scree plot and the other is called the
Component or Factor plot. The Scree plot tells us which variable or groups of variables are statistically important and should be retained. The component plot, however, represents loadings of the variables on the components after they are extracted.

\section{Data Analysis}

The questionnaire used in this study was a five-point Likert scale questionnaire with 30 questions. The reliability of this data collection instrument was $r=.803$, as shown in Table 4.1 below. Pallant (2013) suggests that $r$ values above .70 are large enough for the reliability of questionnaires.

Table 4.1. Reliability of the Questionnaire.

\begin{tabular}{ll}
\hline Reliability Statistics & N of Items \\
\hline Cronbach's Alpha & 30 \\
\hline .803 & \\
\hline
\end{tabular}

PCA was used four times in this study. In the first case, it was used to plot all of the variables on the component plot and around the vectors. This was done to show that there might be variables in each category that do not correlate with each other and do not load on their respective components rather load on the other component or fall somewhere in between. In the second case, PCA was run without the confounding variables, i.e., non-correlating variables. The confounding variables were the ones whose strength of correlation with any other variable and the principle component to which they belonged did not exceed .3, a criterion set by statisticians. The second instance of running PCA could have given us a much clearer picture of what was going on with respect to the loadings of variables on the two principle components. It should be kept in mind, however, that many of the non-correlating variables, as their mean values represented, were very important ones to which respondents had assigned some of the greatest values. This means that, the results needed to be interpreted with respect to the roles that these variables play in relation to foreign language learning success not just by whether they correlate with other variables or not. The third and fourth occasions of running PCAs were related to exploring the variables' interactions within the external and internal groups. Table 4.2 represents the KMO and Bartlett's values for the total data in this study.

Table 4.2. KMO Test of Sampling Adequacy and Bartlett's Sphericity.

\begin{tabular}{lll}
\hline KMO and Bartlett's Test & \\
\hline \multicolumn{3}{l}{ Kaiser-Meyer-Olkin Measure of Sampling Adequacy. } \\
& Approx. Chi-Square & .626 \\
\multirow{2}{*}{ Bartlett's Test of Sphericity } & df & 998.899 \\
& Sig. & .000 \\
\hline
\end{tabular}

According to Field (2009), the value of KMO test of adequacy of sampling should be above the bare minimum of .5 for us to be able to run PCA. Bartlett's measure, tests whether the correlation matrix is an identity matrix (that is, if 
there is any variable that does not correlate with any other variable) or not. Identity matrices are not appropriate for PCA tests. So, we need some correlations between variables for PCA to work but this correlation should not be very high which would result in multicolinarity or singularity.

Another index to be checked for is Determinant of the correlation. The value of Determinant of the correlation is important for rejecting multicollinarity and singularity. This value which is given at the bottom of the Correlation Matrix (which is not given here for its big size) must be smaller than .05 for us to be able to reject the existence of multicollinarity and singularity. In the case of our data the Determinant's value was equal to zero.

Anti-image Covariance is another necessary index which shows the KMO values for individual questions, that is, the adequacy of the number of responses given to each question in the questionnaire. These values fall on the diagonal of Anti-image table and necessarily must be above .5. The heavily shaded values in the portion of the Anti-image covariance table that is given below indicate the magnitudes of this index for individual questions in our data.

Table 4.3. Anti-image Covarince.

\begin{tabular}{lllllllll}
\hline & Motivation & .651 & -.198 & .092 & -.017 & -.081 & .075 \\
& parental & -.198 & .556 & -.103 & -.079 & .057 & -.104 \\
Anti-image & influence & & & & & & \\
Covariance & Intelligence & .092 & -.103 & .627 & -.184 & .016 & .190 \\
& Teachers & -.017 & -.079 & -.184 & .632 & -.075 & -.085 \\
& Attitude & -.081 & .057 & .016 & -.075 & .556 & -.096 \\
& social class & .075 & -.104 & .190 & -.085 & -.096 & .618 \\
\hline
\end{tabular}

The Total Variance Explained table is an additional table that shows the eigenvalues of the variables. Eigenvalue can be conceived of as the ratio of the length of the data in a scatter plot to its breadth represented by perpendicularly crisscrossing lines. The larger this value is the more loading it can be concluded to have on one of the principle components. According to Field (2009), the table of Total Variance Explained lists the eigenvalues associated with each linear variable, i.e., each question in the questionnaire, before and after extraction and also after rotation. The eigenvalue associated with each variable represents the amount of variance explained by that variable.

Variables in the TVE table are listed in a descending order with variables on top having the largest eigenvalues. In the Extraction Sums of Squared Loadings column, the only difference with the previous column is that the values for the discarded variables are ignored. The final column displays the eigenvalues of the variables after they are rotated. Direct Oblimin rotation was the procedure used in this analysis because there were significant correlations between some variables belonging to different components. Verimax is the best choice when variables loadings on different components do not correlate with each other significantly. The following table shows the Rotation Sums of Squared Loadings after rotation was done. Please note that like the Anti-image Covariance table, only the top part of the table is presented here. The deleted section only shows the initial eigenvalues of the remaining variables.

Table 4.4. Eigenvalues of Variables after They Are Rotated.

\begin{tabular}{|c|c|c|c|c|c|c|c|c|c|}
\hline \multirow{2}{*}{ Component } & \multicolumn{3}{|c|}{ Initial Eigenvalues } & \multicolumn{3}{|c|}{ Extraction Sums of Squared Loadings } & \multicolumn{3}{|c|}{ Rotation Sums of Squared Loadings } \\
\hline & Total & $\%$ of Variance & Cumulative \% & Total & $\%$ of Variance & Cumulative \% & Total & $\%$ of Variance & Cumulative \% \\
\hline 1 & 4.665 & 15.551 & 15.551 & 4.665 & 15.551 & 15.551 & 3.403 & 11.343 & 11.343 \\
\hline 2 & 2.133 & 7.109 & 22.659 & 2.133 & 7.109 & 22.659 & 3.395 & 11.316 & 22.659 \\
\hline 3 & 2.033 & 6.775 & 29.435 & & & & & & \\
\hline 4 & 1.838 & 6.126 & 35.561 & & & & & & \\
\hline 5 & 1.598 & 5.328 & 40.889 & & & & & & \\
\hline 6 & 1.469 & 4.898 & 45.787 & & & & & & \\
\hline
\end{tabular}

Field (2009) argues that PCA "works on the initial assumption that all variance is common; therefore, before extraction the communalities are all 1" (p. 661). However, once principle components are extracted, we have a better idea of how much variance is common. For example, in the part of the Communalities table that follows, we can say that $.114 \%$ of the variance associated with the first question is common or shared variance.

Table 4.5. Communalities of Variables.

\begin{tabular}{lll}
\hline Communalities & & \\
\hline & Initial & Extraction \\
\hline Motivation & 1.000 & .114 \\
parental influence & 1.000 & .331 \\
Intelligence & 1.000 & .141 \\
Teachers & 1.000 & .233 \\
Attitude & 1.000 & .142 \\
\hline
\end{tabular}

As it was said, SPSS provides a couple of graphs in addition to tables in PCA. One of the very useful graphs produced is the Scree plot. This plot shows the importance of each variable schematically. Usually, there are one or a few variables that have substantial loadings on the principle components and occupy the highest points on the Scree plot. Variables with relatively low eigenvalues, of which usually there are many, fall after the sharp descent or point of inflexion and tail off with a mild slope. The Scree plot that follows shows the loadings of variables in this study diagrammatically. There are two points of inflexion, as it can be seen, one after the second variable and the other after the third variable. This suggests that there might have been two principle components, as we had speculated initially. The eigenvalue of the variable with the highest loading is close to 5 while the eigenvalues of variables in the first and second inflexion points are around 2. These variables can be identified by the means of the responses to questions if they are arranged from the biggest to the smallest. In the case of 
our data, the first two largest loadings belonged to motivation and teachers.

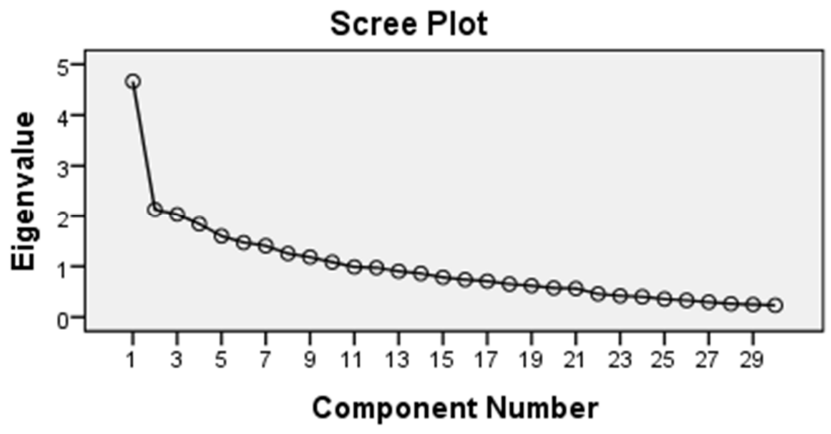

Figure 4.1. Loadings of the variables.

Another important graph that is very informative is the Component Plot, alternatively called Factor Plot. This plot is especially easy to draw when there are only two principle components, because the loadings of variables on them can be represented by two vertical and horizontal axes or vectors. In a two-dimensional component plot, variables that relate to each principle component are plotted around those components represented by the axes. The coordinates of each variable represent the strength of the relationship between that variable and each of the components. That is, the position of each variable says how much it correlates with each of the components. The axes lines range from -1 to 1 which are the outer limits of a correlation coefficient (Field, 2009). In Figure 4.2 below a component plot for the data in this study is given. As it is evident, a cloud of dots covers the area between the two axes on the right top most quarter of the graph. The dots falling on the middle of the cloud represent the variables that not only do not correlate with a particular principle component strongly enough but also do not correlate with other variables of their own type. This finding is confirmed by looking at the Correlations Matrix and provides evidence for accepting our both first and second hypotheses. Remember that our first hypothesis stated that not all variables that are theoretically considered to be internal or external necessarily correlate significantly with variables of their own type. In our Correlation Matrix (which is not given here for its large size) there were at least four internal variables and seven external variables that did not correlate with variables of their own type significantly. This is realizable from the fact that on the component plot variables are not clustered tightly around their respective components. And our second hypothesis stated that there are no internal and external variables that correlate significantly with each other or with the principle component to which they do not belong. Again, considering the odd and even numbers around each vector that represent internal and external variables, respectively, we can see that there are variables of each type clustering around both of the axes. This means that there, indeed, had been variables of different types that correlated significantly with each other and with the principle component to which they did not belong.

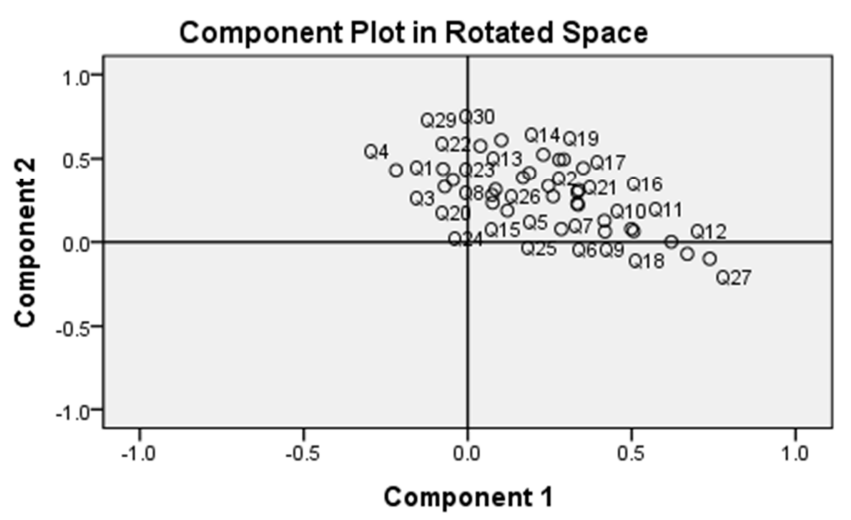

Figure 4.2. Components and their contributing variables.

Strangely enough, the non-correlating variables are some of the most important variables as rated by the respondents. The results obtained in the Rotated Component Matrix below too show variables of different nature having loadings on the Component to which they do not belong conceptually.

Table 4.6. Rotated Loadings of Variables on Components.

\begin{tabular}{|c|c|c|}
\hline \multicolumn{3}{|l|}{ Rotated Component Matrix ${ }^{a}$} \\
\hline & \multicolumn{2}{|c|}{ Component } \\
\hline & 1 & 2 \\
\hline Beliefs & .738 & \\
\hline job market & .670 & \\
\hline Politics & .621 & \\
\hline risk-taking ability & .506 & \\
\hline Personality & .499 & \\
\hline social class & .419 & \\
\hline Press & .417 & \\
\hline first language & .338 & .310 \\
\hline Autonomy & .337 & \\
\hline analytical perception & .334 & \\
\hline $\begin{array}{l}\text { Friends } \\
\text { degree of hopefulness }\end{array}$ & .334 & \\
\hline group work & & .610 \\
\hline early start & & .575 \\
\hline Films & & .524 \\
\hline parental influence & & .495 \\
\hline Anxiety & & .494 \\
\hline participation & .352 & .443 \\
\hline Age & & .438 \\
\hline Teachers & & .431 \\
\hline competitiveness & & .413 \\
\hline $\begin{array}{l}\text { openness to innovation and new } \\
\text { methods }\end{array}$ & & .385 \\
\hline Intelligence & & .373 \\
\hline L2 curriculum & & .335 \\
\hline Motivation & & .331 \\
\hline Institution & & .313 \\
\hline Internet & & \\
\hline Attitude & & \\
\hline teaching resources & & \\
\hline persistence & & \\
\hline
\end{tabular}

The non-correlating variables are questions addressing motivation, intelligence, teachers, social class, autonomy, institutions, friends, persistence, the Internet, teaching resources, and L2 curriculum with mean values of 4.80, 3.97, $4.18,3.42,3.52,3.5,3.15,4.11,3.80,3.68,3.17$, respectively. Some of these variables are internal and others external. The 
empty spaces are there because correlations between the variable and the principle components had been below. 3 .

This state of affairs, however, does not reject the idea that, generally speaking, there are two principle components. To show that there are specific groups of variables that load on just one component we can discard our non-correlating variables and run PCA one more time. The Component Plot and the Rotated Component Matrix resulting from this pruning process will be more revealing as can be seen below in Figure 4.3 and Table 4.7.

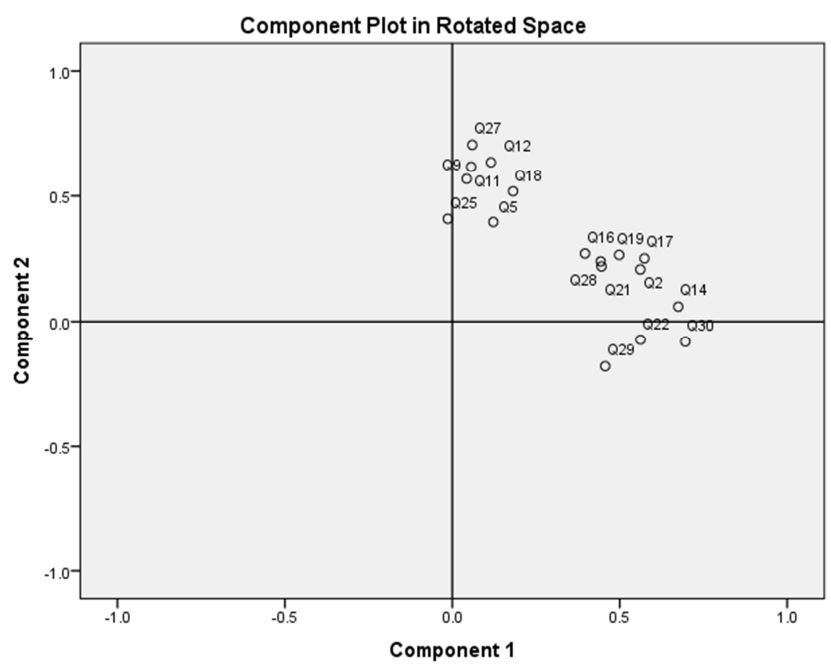

Figure 4.3. Components and their contributing variables after pruning.

Table 4.7. Loadings of Variables on Components after Pruning.

\begin{tabular}{lll}
\hline Rotated Component Matrix $^{\mathbf{a}}$ & & \\
\cline { 2 - 3 } & Component & \\
\cline { 2 - 3 } & $\mathbf{1}$ & $\mathbf{2}$ \\
\hline group work & .698 & \\
Films & .672 & \\
early start & .594 & \\
parental influence & .555 & \\
participation & .529 & \\
Age & .525 & \\
first language & .478 & \\
Press & .389 & \\
Beliefs & & .720 \\
job market & & .647 \\
risk-taking ability & & .608 \\
personality & & .569 \\
Politics & & .527 \\
degree of hopefulness & & .419 \\
Attitude & & .400 \\
\hline
\end{tabular}

To test our third research hypothesis we needed to run an Independent-samples t-test to find out if different variable types had been treated, i.e., rated, differently by EFL learners with respect to their importance or not. Before running this test it would be better for us to know that the grand mean of the scores assigned to the internal variables was 3.767 and the grand mean of the scores assigned to the external variables was 3.499 and this is while only three external variables, namely, politics, friends, and parental influence, by mean scores of $2.71,3.03$, and 3.15 , respectively, gathered low mean scores compared to other external variables. If students had enough information about the role of politicians in setting educational goals, the role that parents play in their children's learning of English as a foreign language, and in developing positive attitudes toward this language, and the role that peers play in many cooperative learning contexts, their responses could have favored external variables. Table 4.8 shows the lack of significant difference in the importance assigned to internal and external principle components by respondents in this study.

Table 4.8. Independent-samples T-test Comparing Means of Internal and External Variables.

\begin{tabular}{lllllll}
\hline \multicolumn{1}{l}{ Independent Samples Test } \\
\hline & $\begin{array}{l}\text { Levene's Test for } \\
\text { Equality of Variances }\end{array}$ & \multicolumn{2}{l}{$\begin{array}{l}\text { t-test for Equality of } \\
\text { Means }\end{array}$} \\
\cline { 2 - 7 } & $\mathbf{F}$ & Sig. & t & df & Sig. (2-tailed) \\
\hline $\begin{array}{l}\text { Equal variances } \\
\text { assumed }\end{array}$ & .990 & .328 & 1.897 & 28 & .068 \\
\hline
\end{tabular}

The result obtained from running Independent-samples ttest convinces us that the mean values of the students' responses to different types of questions did not differ from each other significantly which pushes us to accept our third hypothesis, that is, the importance of internal and external variables from the respondents' perspectives had almost been the same.

Another thing that could be investigated in relation to the questions in the questionnaire was if the internal and external components themselves are divisible. Answering this question could enable us to either reject our fourth research hypothesis which was: Internal and external variables are divisible to cognitive and affective and curricular and environmental, respectively, or accept it. Since, we have already become familiar with the workings of PCA, it would not be very difficult to interpret the results reported below with minimum explanation needed.

To begin with, the internal and external variables needed to be separated from each other. It was said in section three that the questionnaire was divisible to odd-even variables with odd numbers representing the internal and even numbers representing the external variables.

Running a PCA on the internal variables returned a nonsignificant Determinant value of .124 below the Correlation Matrix. This meant that the assumptions of multicolinarity and singularity were not violated and that the data was appropriate for running PCA. The KMO test, also, with a value of .641 was above the bare minimum of .5, which is the lowest limit for the adequacy of sampling. The significance level of the Bartlet's Test of Sphericity, likewise, was below .05 which meant that all variables correlated with each other to some extent. Information related to the KMO and Bartlett's Sphericity tests are given in Table 4.9 below.

Communalities table for internal variables is ignored here, as it will be ignored for the external variables, because the kind of information they provide for us is not vital to our understanding of the remaining of this study. Table 4.10 represents the eigenvalues or loadings of the variables on the 
principle components before and after extraction and after rotation. There are many variables that have eigenvalues above 1 in this table, but since we had set PCA to extract only two variables for us after rotation, only the loadings of two variables are given in the third column.

Table 4.9. Tests of Adequacy of Sampling and Sphericity for Internal Variables.

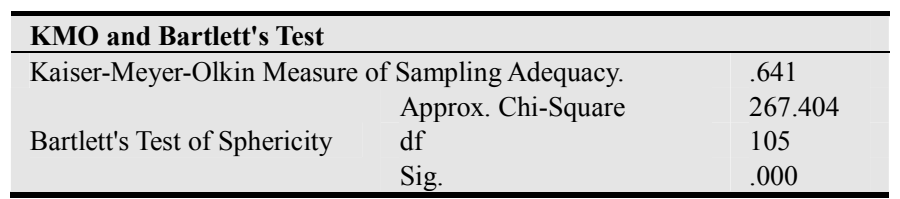

It was said that KMO is a measure of sampling adequacy, but this measure is used at two stages: first, to see if the number of respondents to the questionnaire was enough and second, to see if every question was attempted by enough respondents. While the KMO and Bartlett's Test of Sphericity provide answer for the first question, the answer to the second question can be found in the Anti-image Covariances table. The values of the Anti-image Covariances should also go beyond .5 for PCA to work. These values for internal variables are represented by the heavily shaded areas on the diagonal of the Anti-image Covariances table below.

Table 4.10. Eigenvalues of Internal Variables after They Are Rotated.

\begin{tabular}{llllllll}
\hline \multicolumn{2}{l}{ Total Variance Explained } & & & & \\
\hline \multirow{2}{*}{ Component } & \multicolumn{2}{l}{ Initial Eigenvalues } & & \multicolumn{2}{c}{ Extraction Sums of Squared Loadings } & \multicolumn{2}{c}{ Rotation Sums of Squared Loadings } \\
\cline { 2 - 7 } & Total & \% of Variance & Cumulative \% & Total & \% of Variance & Cumulative \% & Total \\
\hline 1 & 2.857 & 19.045 & 19.045 & 2.857 & 19.045 & 19.045 & 2.695 \\
2 & 1.446 & 9.639 & 28.684 & 1.446 & 9.639 & 28.684 & 1.848 \\
3 & 1.378 & 9.185 & 37.869 & & & \\
4 & 1.273 & 8.488 & 46.357 & & & \\
5 & 1.147 & 7.644 & 54.001 & & & \\
\hline
\end{tabular}

Table 4.11. Anti-image Covariances.

\begin{tabular}{|c|c|c|c|c|c|c|c|c|c|c|c|c|c|c|c|c|}
\hline & & Q1 & Q3 & Q5 & Q7 & Q9 & Q11 & Q13 & Q15 & Q17 & Q19 & Q21 & Q23 & Q25 & Q27 & Q29 \\
\hline \multirow{15}{*}{$\begin{array}{l}\text { Anti-image } \\
\text { Covariances }\end{array}$} & Q1 & $.551^{\mathrm{a}}$ & .057 & -.124 & -.006 & -.113 & .179 & -.109 & -.190 & .017 & -.110 & -.040 & .111 & -.094 & .060 & -.092 \\
\hline & Q3 & .057 & $.604^{a}$ & -.056 & -.088 & -.101 & -.044 & -.070 & .107 & -.001 & -.021 & -.081 & .138 & -.077 & .059 & -.078 \\
\hline & Q5 & -.124 & -.056 & $.658^{\mathrm{a}}$ & -.055 & -.234 & -.202 & .056 & .002 & .093 & -.144 & .032 & -.095 & -.304 & .088 & -.114 \\
\hline & Q7 & -.006 & -.088 & -.055 & $.648^{\mathrm{a}}$ & -.157 & .080 & .026 & -.061 & -.068 & .103 & -.220 & -.048 & -.101 & -.088 & -.236 \\
\hline & Q9 & -.113 & -.101 & -.234 & -.157 & $.630^{\mathrm{a}}$ & -.119 & .106 & -.101 & .121 & -.082 & -.005 & -.011 & .138 & -.282 & .079 \\
\hline & Q11 & .179 & -.044 & -.202 & .080 & -.119 & $.699^{a}$ & -.147 & -.151 & -.048 & -.140 & -.114 & .163 & -.097 & -.200 & -.023 \\
\hline & Q13 & -.109 & -.070 & .056 & .026 & .106 & -.147 & $.666^{\mathrm{a}}$ & .036 & -.011 & -.143 & -.100 & -.182 & -.097 & .021 & -.065 \\
\hline & Q15 & -.190 & .107 & .002 & -.061 & -.101 & -.151 & .036 & $.683^{a}$ & -.162 & .067 & -.148 & .054 & -.047 & .034 & .039 \\
\hline & Q17 & .017 & -.001 & .093 & -.068 & .121 & -.048 & -.011 & -.162 & $.664^{\mathrm{a}}$ & -.352 & -.112 & -.107 & -.076 & -.221 & -.134 \\
\hline & Q19 & -.110 & -.021 & -.144 & .103 & -.082 & -.140 & -.143 & .067 & -.352 & $.676^{\mathrm{a}}$ & -.154 & -.068 & .071 & .060 & .071 \\
\hline & Q21 & -.040 & -.081 & .032 & -.220 & -.005 & -.114 & -.100 & -.148 & -.112 & -.154 & $.694^{\mathrm{a}}$ & .001 & .171 & .024 & .075 \\
\hline & Q23 & .111 & .138 & -.095 & -.048 & -.011 & .163 & -.182 & .054 & -.107 & -.068 & .001 & $.541^{\mathrm{a}}$ & -.115 & -.058 & -.093 \\
\hline & Q25 & -.094 & -.077 & -.304 & -.101 & .138 & -.097 & -.097 & -.047 & -.076 & .071 & .171 & -.115 & $.580^{\mathrm{a}}$ & -.123 & .092 \\
\hline & Q27 & .060 & .059 & .088 & -.088 & -.282 & -.200 & .021 & .034 & -.221 & .060 & .024 & -.058 & -.123 & $.619^{a}$ & .118 \\
\hline & Q29 & -.092 & -.078 & -.114 & -.236 & .079 & -.023 & -.065 & .039 & -.134 & .071 & .075 & -.093 & .092 & .118 & $.495^{\mathrm{a}}$ \\
\hline \multicolumn{17}{|c|}{ Measures of Sampling Adequacy(MSA)a } \\
\hline
\end{tabular}

Table 4.12. Pattern of Internal Variables Showing their Loadings on Principle Components.

\begin{tabular}{lll}
\hline Pattern Matrix $^{\mathrm{a}}$ & & \\
\hline & Component & $\mathbf{2}$ \\
\cline { 2 - 3 } & $\mathbf{1}$ & -.368 \\
\hline Q9 & .724 & \\
Q11 & .660 & \\
Q27 & .567 & \\
Q5 & .550 & \\
Q15 & .483 & \\
Q7 & .385 & \\
Q21 & .371 & \\
Q25 & .326 & \\
Q3 & & .629 \\
Q1 & & .585 \\
Q13 & & .501 \\
Q23 & & .466 \\
Q17 & .314 & .431 \\
Q29 & & \\
Q19 & .361 & \\
\hline
\end{tabular}

Up to this point, we have been talking about the conditions that should be met before running any PCAs. However, to understand about the components and the loadings of variables on them we need to look at Pattern and Rotated Component matrices and Scree and component plots. Table 4.12 shows the Pattern Matrix for the internal variables.

The scree plot shows information on the loadings of the internal variables. The most important graph for us, however, is the component plot that follows it. The component plot shows whether variables cluster around one component or the other or are distributed unpredictably between the two components.

If we call the two principle components of internal variables as affective and cognitive, we can see that only three of the variables have clustered around the vertical component and the rest are bundled around the horizontal axis. This means that even with more specific categorization of variables the respondents' answers to the questions do not 
converge or diverge on the basis of variables' nature. Ignoring other details, the Component plot for the external variables shows even a more confusing picture of the loadings of this type of variables on the curricular and environmental components, as can be seen in Figure 4.6.

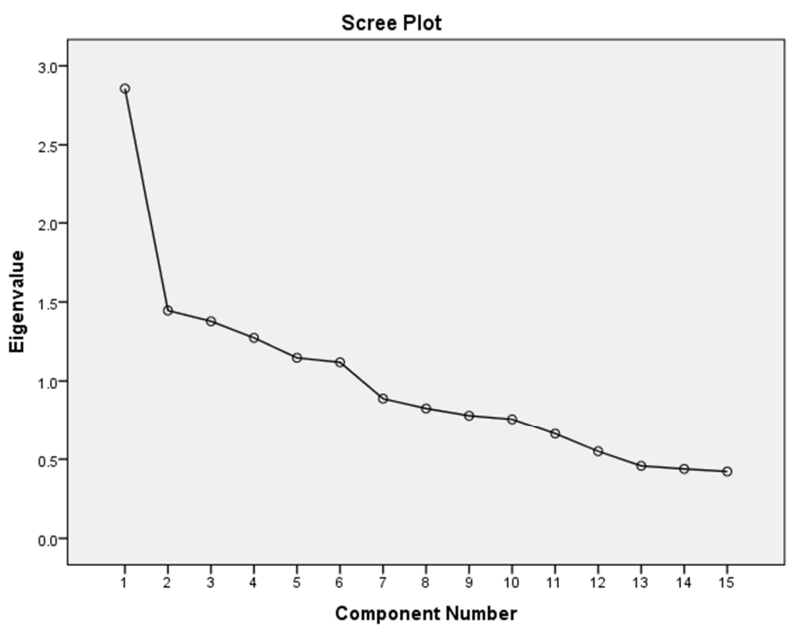

Figure 4.4. Scree plot for the internal variables.

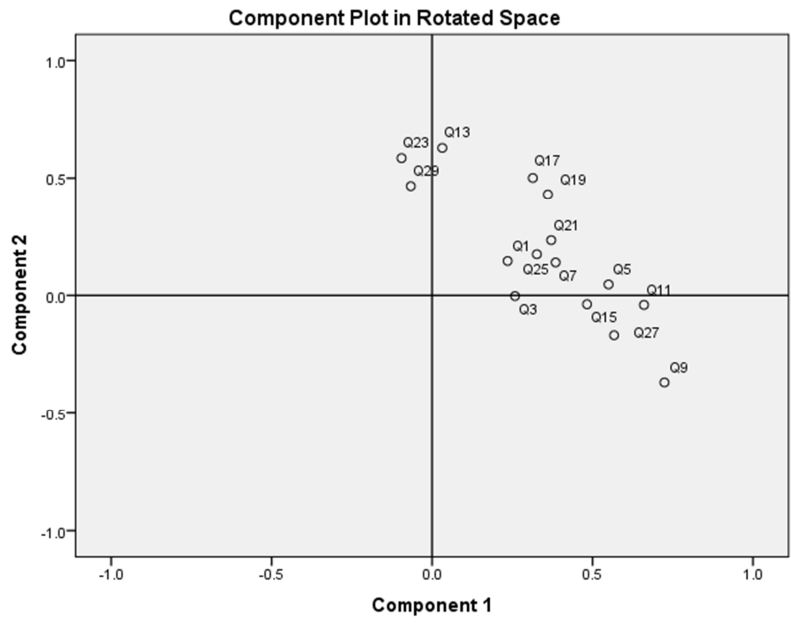

Figure 4.5. Component plot for the internal variables.

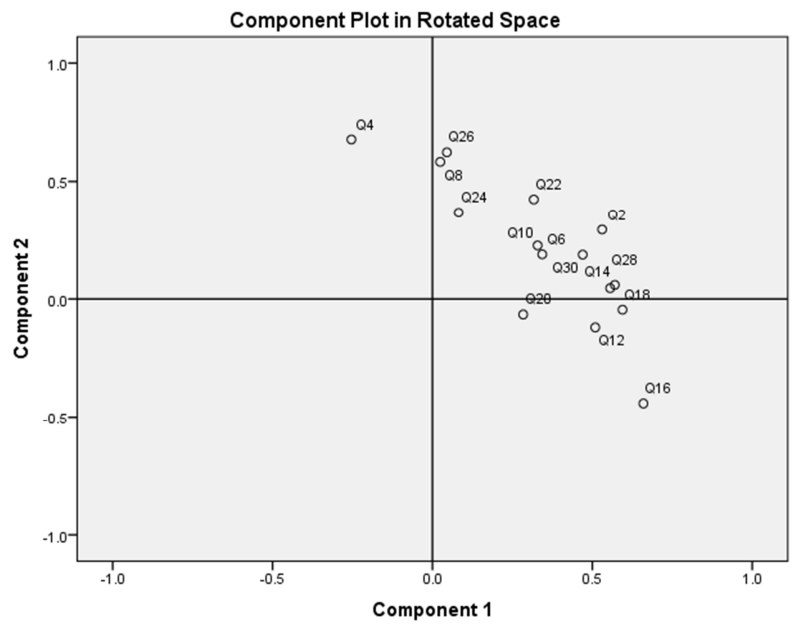

Figure 4.6. Component plot for the external variables.
These findings drive us to the conclusion that our fourth hypothesis concerning the divisibility of the internal and external variables to cognitive and affective and curricular and environmental, respectively, is not tenable with respect to the amount of importance assigned to them although this division might be valid theoretically. That is, students do not accord much importance to a variable simply because it is internal or external, rather they look back at their own language experience and try to figure out what it was that made them a successful learner or what discouraged them from learning be it internal or external.

\section{Conclusion and Discussion}

The finding that there were two principle components is not very important because we already knew about it. What is important is that to determine the elements of success in foreign language learning one should not exclusively concentrate on variables that load on one principle component or the other but to concentrate on both of them and even variables that load on none of them heavily. Alternatively, one could focus on variables that although belonging to a particular category, do not correlate highly with variables of the same nature.

One reason for this is that variables that theoretically are related to each other and fall in the same category do not necessarily correlate highly with each other and even with the principle component that represents them. For example, in the case of this study motivation, which had the highest mean score among all of the variables, did not correlate highly with the internal variables like intelligence and persistence. It did not load heavily on the internal principle component either, as can be seen in Table 4.6. On the other hand, 'teachers' variable which was the second most important variable from the respondents' perspective did not correlate highly with teaching resources and institutions and did not load heavily on the external component either, as is visible again in Table 4.6. These findings altogether suggest that categories should not be the basis of our judgment by saying that, for example, internal variables are more important than external variables merely because these are emphasized more in the literature. What matters, is paying balanced attention to both categories of variables and exploring their effects.

\section{References}

[1] Attitude. (2009). In Encyclopedia Wikipedia online. Retrieved from http://en.wikipedia,org/second_language_acquisition/attitue.

[2] Brown, H. D. (2007). Principles of Language Learning and Teaching (5th ed.). New York: Pearson Education, Inc.

[3] Brown, J. D. (1995). The elements of language curriculum. Boston, Massachusetts: Heinle \& Heinle Publishers.

[4] Cheng, H., \& Dörnyei, Z. (2007). The use of motivational strategies in language instruction: the case of EFL teaching in Taiwan. Innovation in Language Learning and Teaching, 1(1), $153-174$. 
[5] Cohen, A. D. (2010). Focus on language learner: Style, strategies, and motivation. In N. Schmitt (Ed.), An introduction to applied linguistics (2nd ed.). London: Hodder \& Stoughton Ltd.

[6] Dörnyei, Z. and Csizer, K. (1998). Ten commandments for motivating language learners: Results of an empirical study. Language Teaching Research, 2(3), 203-229.

[7] Ellis, R. (2008). The study of second language acquisition (2nd ed.). New York: Oxford University Press.

[8] Field, A. (2009). Discovering statistics using SPSS (3rd ed.). London: Sage Publications Ltd.

[9] Gardner, R. C. (1985). Social psychology and second language learning: The role of attitudes and motivation. London: Edward Arnold.

[10] Gass, S., \& Selinker, L. (2008). Second language acquisition (3rd ed.). New York: Routledge.

[11] Ismaili, M., (2013). The effectiveness of using movies in the EFL classroom: A study conducted at South East European University. Academic Journal of Interdisciplinary Studies, 2 (4), 110-118

[12] Karim, K. (2003). First language (L1) influence on second language (L2) reading: The role of transfer. Proceedings of the 19th Northwest Linguistics Conference. (pp. 324-347). Victoria, B.C.: Victoria.

[13] Khanchali, M., \& Zidat, A. (2011). The impact of the Internet on the development of students' writing. Revue des Sciences Humaines 21, 51-62.

[14] Kinginger, C., \& Farrell, K. (2004). Assessing development of meta-pragmatic awareness in study abroad. Frontiers: The Interdisciplinary Journal of Study Abroad, 10, 19-42.

[15] Lewis, M., \& Hill, J. (1985). Practical techniques for language teaching. London: Language Teaching Publications.

[16] Madrid, D. (1995). Interanl and external factors in language teaching. Actas de las 1I Jornadas de Estudios Ingleses. Universidad de Jaen, 2 (2), 59-82.
[17] Nation, I. S. P., \& Macalister, J (2010). Language curriculum design. New York: Routledge.

[18] Nunan, D. (1988). Syllabus design. New York: Oxford University Press.

[19] Nurul Islam, M. (2011). Independent English learning through the Internet. Journal of Language Teaching and Research, 2 (5), 1080-1085.

[20] Ortega, L. (2009). Understanding second language acquisition. London: Hodder Education.

[21] Pallant, J. (2013). SPSS survival manual. New York: Open University Press.

[22] Richards, J. C. (2001). Curriculum development in language teaching. New York: Cambridge University Press.

[23] Robinson, P., \& Ellis, N. C. (2008). An introduction to cognitive linguistics, second language acquisition, and language instruction. In P. Robinson, \& N. C. Ellis (Eds.). Handbook of cognitive linguistics and second language acquisition. New York: Routledge.

[24] Segalowitz, N. (1986). Skilled reading in the second language. In J. Vaid (Ed.). Language Processing in bilinguals: Psycholinguistic and Neuropsychological Perspectives. Hillsdale, NJ: Lawrence Erlbaum.

[25] Siegel, J. (2003). Social context. In C. J. Doughthy, \& M. H. Long (Eds.). The handbook of second language acquisition. Oxford: Blackwell Publishing Ltd.

[26] Stipek, D. J. (2002). Motivation to learn: Integrating theory and practice (4th ed.). Boston, MA: Allyn and Bacon.

[27] White, R. (1988). The ELT curriculum: Design, innovation and management. Oxford: Basil Blackwell Ltd.

[28] Woolfolk, A. E., Winne, P. H., \& Perry, N. E. (2003). Educational Psychology (2nd ed.). Toronto: Pearson Education Canada Inc. 